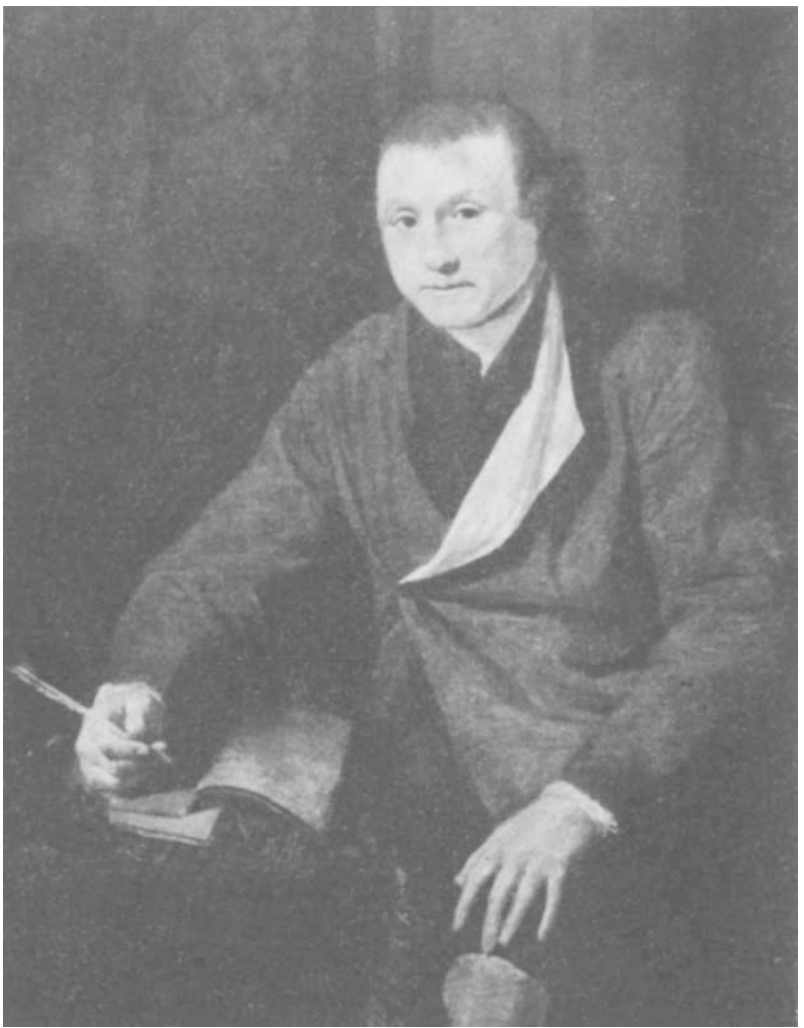

Portrait of John Hunter by his brother in law, Robert Home.

In 1761, following a bout of ill-health, Hunter set off with the expeditionary force to Belleisle and Portugal. His surgical work there was to form the basis of his greatest book, On the Blood, Inflammation and Gun-shot Wounds, published posthumously in 1794. This important physiological work contains his observations on coagulation, and on previously little understood subjects such as the union of wounds, the formation of pus, and the regeneration of the skin. On Bolleisle, Hunter also seized the opportunity to make observations of natural history which he was to follow up in later years. In particular, his interest in hibernation began there, and he conducted oxperiments upon the organs of hearing in fish. Some of this work was published in the Philosophical Transactions (he became FRS in 1767) and some was incorporated into his Observations on Certain Parts of the Animal Oeconomy, 1786. On his return from Portugal he made a catalogue of the two hundred and fifty preparations which he had already collected. His notes on the geological formation of the mountainous areas in Portugal were later used in his Observations on Geology, published by Richard Owen in 1859 .

Back in London in 1763, Hunter began his life's work as a surgeon and natural historian, and made the great museum for which he is justly famous. Never before, and seldom since, has a single individual set out and succeeded in so great a scheme of collection. Hunter's plan was so to arrange his preparations that they showed tho similarities and differences between the bodily systems in a wide variety of species: the way in which structure is adapted to function; how generation occurs; and the pathological effects of accident and disease.

That he succeeded was due to his enormous industry and to his utter devotion to the task. Unfortunately, many of his specimens were destroyed in 1941, but enough remain to show his plan and they have been reorganized by Miss Dobson herself.

Miss Dobson gives a good account of Hunter's researchos, and a useful chronological list of his writings, which incidentally shows very clearly his leaning towards natural history. No less than thirty titles relate to animal anatomy and physiology, rather more than are listed for the human subject.

This book is a definitive biography of a great surgeon, naturalist and toacher. The excellent references and bibliography add to its value.

K. Bryn Thomas

\section{THE DOCTOR'S DILEMMA}

\section{Criteria of Brain Death}

Selection of Donors for Transplantation. By Palle JuulJensen. Pp. 57. (Munksgaard: Copenhagen, January 1970.) 22 D.kr.

Death outside hospital usually offers little difficulty in diagnosis if respiration and circulation have coasod. There are exceptions, of course, as in the recent reports of reanimation of hypothermic patients believed dead.

In hospitals, and particularly in those catering for severe head injuries, the problem is more acute. Patients with deterioration of respiration and circulation are often sustained by respirators and intravenous vasopressors. Although some may avoid the dilemma of "switching off" by never using resuscitative measures for patients who are moribund or where a fatal issue is expected, increasing experience shows that prognosis cannot always be so sure and energetic resuscitation may preserve the patient's life, at least while on the respirator. The problem does not continue long, however, bccause ultimately the blood pressure cannot be sustained and the heart stops. This is a trying time for relatives and nursing staff and not infrequently doctors are urged by the nurses to discontinuo the supportive measures. To many, this seems an almost insoluble ethical dilemma rendered moro acute by the realization that the optimum time for taking organs for transplantation may be passing.

We might porhaps develop a now concept of death rather than the classical one of a state where spontancous heart beat and respirations have ceased. It seems evident that the one important feature is the conscious level of the pationt and thus there is a need to develop the concept of "brain death" to replace "clinical death". Mediaeval notions that the heart is the scat of emotions and soul are replaced by the modern concept that the brain is the organ of the mind.

Dr Juul-Jensen has written a little book devoted to this problem and the diagnosis of brain death. It comes from the Department of Clinical Neurophysiology in the University Hospital at Aarhus, Denmark, and is based on the author's experience with isoelectric electroencephalograms in seventy-two patients. Nearly half the book is devoted to eight selected case histories and the general thesis of the work is that an isoelectric EEG is a reliable indication of brain death. Although the EEG finding is a sine qua non, Jensen is careful to point out that other criteria must be used, such as the depth of coma and caloric tests. He also points out the difficulties in diagnosing brain death in patients who are hypothermic or poisoned and argues for tho almost exclusive use of neurosurgical patients as donors for organ transplant. Of his seventy-two cases only one patient survived, and although this patient had an isoelectric EEG he did not satisfy all the criteria outlined by Jensen. The author believes that the central point is the clinical evaluation but, helpfully and perhaps optimistically, says that brain death can unquestionably be diagnosed in neurosurgical patients on the basis of the criteria outlined.

The printing is clear and the illustrations confined to the flat EEGs recorded in these cases. The translation from the Danish is into unexceptionable English and this modest work will be appreciated by all who have to deal with the dilemma of supportive therapy and the seloction of donors for transplantation. EDWARD HITCHCOCK 